\title{
Growth of radiata pine families in nursery and two years after field establishment
}

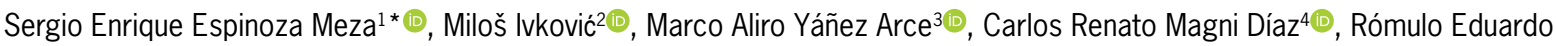 \\ Santelices Moya ${ }^{1 \oplus}$, Antonio María Cabrera Ariza ${ }^{1 \oplus}$
}

${ }^{1}$ Universidad Católica del Maule/Facultad de Ciencias Agrarias y Forestales, Av. San Miguel, 3605 - 3460000 Talca - Chile.

${ }^{2}$ Southern Tree Breeding Association Inc, 39 Helen St - Mt. Gambier - SA 5290 - Australia.

3Universidad de Talca/Núcleo Científico Multidisciplinario, 2 Norte 685 - Talca - Chile.

4Universidad de Chile/Facultad de Ciencias Forestales y de la Conservación de la Naturaleza, Av. Santa Rosa, 11365

-8820000 - La Pintana - Chile.

*Corresponding author <espinoza@ucm.cl>

Edited by: Rafael Rubilar Pons

Received May 16, 2018

Accepted October 28, 2018
ABSTRACT: Pinus radiata D. Don is the most widely planted exotic species in Australia, Chile, New Zealand and Spain. In this study, growth and survival of $P$. radiata were compared in 30 open pollinated families grown under two contrasting watering regimes in nursery (well-watered cf. water-stress conditions) and planted on a drought-prone site with Mediterranean climate in central Chile. This study assessed phenotypic plasticity in growth and survival at nursery stage and two years after establishment in the field. Family plasticity at nursery stage was estimated by the angular phenotypic change index (APCI), while the relationship between nursery and field traits was estimated by genetic correlations $\left(r_{g}\right)$ and the Pearson coefficient of correlation $\left(r_{x y}\right)$. Families presented high plasticity in diameter, height, and survival at nursery stage. Out of 30 families, eight exhibited over $80 \%$ survival in the well-watered treatment, but less than $20 \%$ survival in the water-stress treatment. As expected, growth traits and survival were positively correlated $\left(r_{g}\right.$ and $\left.r_{x y}>0.65\right)$ between both nursery environments. However, for growth, most genetic and phenotypic correlations between combinations of nursery treatments versus the field test were negative or not significant. As there was no detectable pattern of nursery-field correlations regarding to combinations of nursery treatments and test site, the need to include more stable families and genotypes to an appropriate developmental stage at nursery is discussed.

Keywords: Pinus radiata, survival, phenotypic plasticity, nursery-field correlations, dry sites

\section{Introduction}

Radiata pine is the most planted forest species in Chile, covering an estimated area of 1.39 million ha (INFOR, 2018). Plantations have been successful in Mediterranean climate areas where summers are relatively dry (Mead, 2013). However, summer droughts or soil moisture deficits may greatly reduce productivity of the species. Because climate change may increase drought events in the summer season (IPCC, 2013), there is a need to identify the best planting material for droughtprone sites as early as possible in the selection process.

Some studies have supported the hypothesis that phenotypic performance of different genotypes under field conditions can be predicted at early developmental stages in nursery. The success of prediction, among other factors, is related to how well the nursery growth conditions simulate field conditions. Cannell et al. (1978) found high growth stability of Pinus taeda L. families cultured for one growing season at nursery and then at eight years after planting (measured as a positive correlation of family means between both environments). Similarly, Tan et al. (1995) found high and positive correlation for growth traits in Picea mariana [Mill.] B.S.P. families cultivated in water-stressed nursery environment during two growing seasons and then 16 years after establishment in a dry site. Conversely, Jansson et al. (1998) found only weak-to-moderate positive correlations in Pinus sylvestris L. between seedlings cultured for three growing seasons at nursery and traits after 20 years in the field. According to Harfouche (2003), simulating field limiting factors at nursery does not always improve correlations between growth at nursery and in the field. The developmental stage of plants tested is also an important factor that contributes to early selection (Lascoux et al., 1993). In this respect, Jansson et al. (2005) found no consistent correlation between nursery data (i.e., growth chamber experiment) and 24-year-old-field data in Picea abies L. This situation may be attributed to the fact that growth is regulated by ontogenic changes (Hodge and White, 1992), influencing nursery-field correlations (Williams, 1987).

Genetic differences in growth and survival under drought stress at nursery and in drought-prone sites have been documented in $P$. radiata (Espinoza et al., 2014, 2017). However, prediction of performance of different families in the field, based on early evaluation at the nursery stage, has not been explored. In this study, we assessed the relationship for growth and survival of $30 P$. radiata families at nursery stage and two years after establishment in a drought-prone site.

\section{Materials and Methods}

\section{Plant material}

The material used in this study consisted of a random subset of 30 open-pollinated radiata pine families from different breeding generations belonging to Forestal Mininco S.A. radiata pine breeding program in Chile. To analyze the relationship between 6-month-old seedlings and 2-year-old trees, two experiments were conducted independently in a nursery and in an experimental field site.

\section{Nursery experiment}

Seeds of 30 families were cultivated at nursery for 165 days. The seeds were sown in Oct 2012 in $140 \mathrm{~mL}$ 
pots (88 cavities per holding tray) with a mixture of composted bark of $P$. radiata pine and perlite (particle size 0.5-3 mm) (8:2 v:v), combined with a slow-release fertilizer (Basacote plus $6 \mathrm{M}$, at $3 \mathrm{~kg} \mathrm{~m}^{3}$ ). The experiment was divided into two phases. First, a growing phase (watering-to-container capacity, average temperature and relative humidity between $14-20{ }^{\circ} \mathrm{C}$ and 60-70 \%, respectively) that lasted until the plants were 120 days old. Second, the seedlings were submitted to two watering regimes (well-watered and water-stress treatments) during 45 days, as described by Espinoza et al. (2013). In the well-watered treatment, seedlings were kept under the same watering regime as previously mentioned, while the water-stress treatment comprised three 13-day cycles of water retention plus two days of watering between each cycle. Replicates were arranged for all seedlings to receive the same light and micro climatic conditions, except for the watering regime. Irrigation was carried out using micro sprinklers and an automatic irrigation system set for water seedlings every day and twice per day in the well-watered condition, and every 13 days in the water stress condition. Temperature and relative humidity averaged $17^{\circ}$ and $65 \%$ for the well-watered condition, and $22^{\circ} \mathrm{C}$ and $59 \%$, for the water stress treatment. The predawn water potential $\left(\Psi_{\mathrm{pd}}\right)$ was used as an indicator of the water status in the seedlings. This parameter was measured at the end of the experiment (i.e., day 166) by using a subsample of three seedlings per family per watering regime. Seedlings were excised near the substrate surface and the predawn water potential was measured with a Scholander pressure chamber between 04h00 to 06h00. Seedlings in the well-watered treatment kept an average predawn water potential $\left(\Psi_{\mathrm{pd}}\right)$ of $-0.5 \pm 0.1$ $\mathrm{MPa}$. In the water stress treatment, seedlings reached an average $\Psi_{\text {pd }}$ of $-1.5 \pm 0.1 \mathrm{MPa}$. After the watering treatments were applied, height $(\mathrm{H})$, root collar diameter (D), survival (SUR) (as a categorical trait, i.e., $1=$ alive, $0=$ dead), and shoot ontogeny were measured in all seedlings. Shoot ontogeny was registered in terms of presence or absence of dwarf shoots (Williams, 1987). Later, the survival rate was analyzed as percentages. The experiment was arranged as a split-plot design, with watering regime as the whole plot and family as the sub-plots. The two watering treatments were applied to 30 families $\times 3$ replicates $\times 11$ seedlings per family (i.e., 1,980 seedlings in total).

\section{Field trial}

Another group of seedlings of the same 30 families were independently grown for 10 months (i.e., from Oct 2012 to July 2013) under the same conditions of the growing phase mentioned above. After that, a field trial was established in Aug 2013 at the Alcapan (Los Angeles, central Chile, $37^{\circ} 12^{\prime} \mathrm{S}, 72^{\circ} 10^{\prime} \mathrm{W}, 200 \mathrm{~m}$ a.s.l) on a flat site. The soil at the study site was sandy (93\% sand) with very low water holding capacity (5\% volume at a depth of 3 meters) and low levels of total nitrogen and phosphorus (Huber and Trecaman, 2004). In the site, precipitation occurs mostly in the winter months (553$619 \mathrm{~mm})$; whereas, the summer months are typically hot and dry (maximum summer air temperature from 26 to $\left.28^{\circ} \mathrm{C}\right)$. The dry period lasts longer than seven months. Because of the dry conditions in summer at the study site and good weed control operations, scarce weed vegetation was observed. Site preparation consisted of subsoiling at up to $50 \mathrm{~cm}$ depth. The trial was planted with shovels in July 2013 following a completely randomized block design with nine replicates of 30 families and 9-tree square plots each (i.e. 2,430 seedlings). Seedlings were planted at $3 \times 3 \mathrm{~m}$ spacing, with plant density of 1,111 stems ha ${ }^{-1}$. In Mar 2015, $\Psi_{\text {pd }}$ was measured on a random subsample of 150 trees (i.e. 5 blocks $\times 30$ families $\times 1$ tree per block per family $=150$ trees) with the pressure chamber. Trees kept an average $\Psi_{\text {pd }}$ of $-0.6 \pm$ $0.2 \mathrm{MPa}$. H, D and SUR were measured in all trees two years from planting (i.e. July 2015).

\section{Data analysis}

The phenotypic plasticity of each family at nursery stage was estimated by the angular phenotypic change index (APCI) (Chambel et al., 2007). Briefly, family means for each trait were determined for water stress treatment (on the x-axis) and under the well-watered treatment (on the y-axis), and represented graphically following Pigliucci and Schlichting (1996). This way, each family is represented by a single point based on axes in the same scale. The one-to-one diagonal represents a null phenotypic change (i.e. a flat reaction norm), where the vector with angle $\alpha$ can be interpreted as an index quantifying the phenotypic change. The angle $\alpha$ for any trait is calculated from the arctangent of phenotypic value in well-watered treatment divided by phenotypic value in water-stress treatment. When a vector is on the diagonal (i.e. an APCI value is equals to one, or a $45^{\circ} \alpha$ angle), it represents a family with no plasticity (i.e. equal phenotypic values in both environments). Conversely, if there is a marked difference in the phenotypic value between both environments, the plasticity level of a family is proportional to the APCI values (i.e. $0^{\circ}<\alpha<90^{\circ}$ ). In our experiment, two families exhibited $0 \%$ survival in the water-stress treatment (families 20 and 28) and $82 \%$ survival in the well- watered treatment, which were assigned an APCI value close to zero.

To assess the relationship between nursery and field performances, multivariate analyses were conducted to estimate the genetic correlations for a trait $\left\langle\mathrm{r}_{\mathrm{g}^{\prime}}\right.$ Burdon, 1977) between different combinations of three environments, as follows:

$r_{g}=\frac{\sigma_{A x A y}}{\sqrt{\left(\sigma_{A x}^{2}\right)\left(\sigma_{A y}^{2}\right)}}$

where $\sigma_{A x A y}$ is the additive genetic covariance component between traits $x$ and $y$ (i.e. D, H, and SUR), $\sigma_{A x}^{2}$ is 
the additive genetic variance component for trait $x$, and $\sigma_{A y}^{2}$ represents the additive genetic variance component for trait $y$. Similarly, we used the Pearson coefficient of correlation $\left(r_{x y}\right)$, based on family means, as a measure of the phenotypic correlation. The linear model was:

$$
Y_{i j k l}=\mu+E_{i}+B(E)_{j(i)}+F_{k}+E * F_{i k}+F * B(E)_{j(i) \mathrm{k}}+e_{i j k l}
$$

where, $Y_{i j k l}$ is the measurement, $\mu$ is the overall mean, $E_{i}$ is the fixed effect of the $\mathrm{i}^{\text {th }}$ environment (water stress at nursery, well-watered at nursery, or field trial), $B(E)_{j(i)}$ is the fixed effect of $\mathrm{j}^{\text {th }}$ block nested within the $\mathrm{i}^{\text {th }}$ environment, $F_{k}$ is the random effect of the $\mathrm{k}^{\text {th }}$ family $(k=1$ to 30$), E^{*} F_{i k}$ and $F^{*} B(E)_{j(i) k}$ represent interaction between families and environments and blocks within environments, and $e_{i j k l}$ is the experimental random error.

\section{Results}

\section{Family phenotypic plasticity at nursery stage}

After 165 days of growth, in the water-stress treatment, family averages for $\mathrm{D}, \mathrm{H}$, and SUR were $2.71 \mathrm{~mm}$, $22.5 \mathrm{~cm}$, and $42 \%$, while coefficients of variation were $5.6,13.4$ and $63 \%$ for the same traits. In the well-watered treatment, family averages for $\mathrm{D}, \mathrm{H}$, and SUR were 3.51 $\mathrm{mm}, 26.9 \mathrm{~cm}$, and $100 \%$, while coefficients of variation were $7.7,12.1$ and $9 \%$ for $\mathrm{D}, \mathrm{H}$, and SUR, respectively. In both watering treatments, $100 \%$ of seedlings did not register the presence of dwarf shoots (data not shown). These results highlight the higher variation for survival, when water stress occurs. APCI values reflected differences in plasticity for all traits analyzed. For D and $\mathrm{H}$, the families under study showed high plasticity (Figures $1 \mathrm{~A}, \mathrm{~B})$. APCI family values ranged from 0.87 to 0.98 for $\mathrm{D}$ and from 0.83 to 0.94 for $\mathrm{H}$. In the case of survival, APCI values ranged from 0 to 1.47 (Figure 1C). An APCI value equal to 0 represents families with $0 \%$ survival in the water-stress treatment, but $100 \%$ survival in the wellwatered treatment. This high divergence in APCI values for survival was because eight families exhibited less than $20 \%$ survival in the water-stress treatment. Two of those eight families exhibited no survival in this treatment.

\section{Relationship between growth and survival at nursery and field}

Two years after planting, family averages for $\mathrm{D}$, $\mathrm{H}$, and SUR were $20.1 \mathrm{~mm}, 85.9 \mathrm{~cm}$, and $74 \%$, respectively. Growth traits and survival were highly and positively correlated between nursery environments (i.e., well-watered cf. water stress). Conversely, correlations of traits between nursery environments and the experimental field site varied from null to low negative correlations (Table 1, Figure 2). Genetic correlations $\left(\mathrm{r}_{\mathrm{g}}\right)$ for growth traits were positive in the nursery environments, but negative in the nursery-field combinations. For survival, a positive genetic correlation between nursery water stress and experimental field site was observed

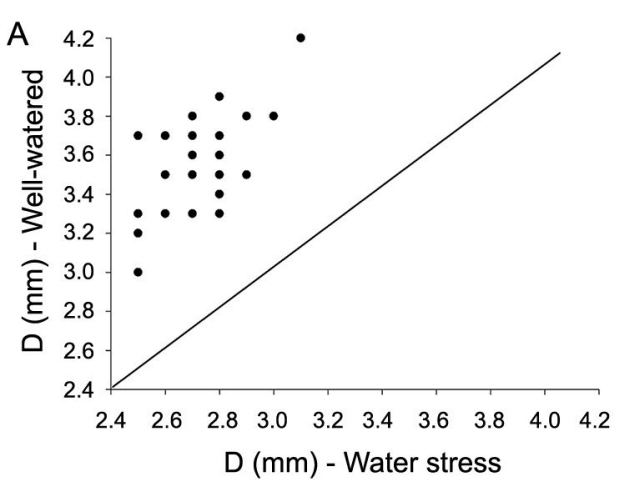

B
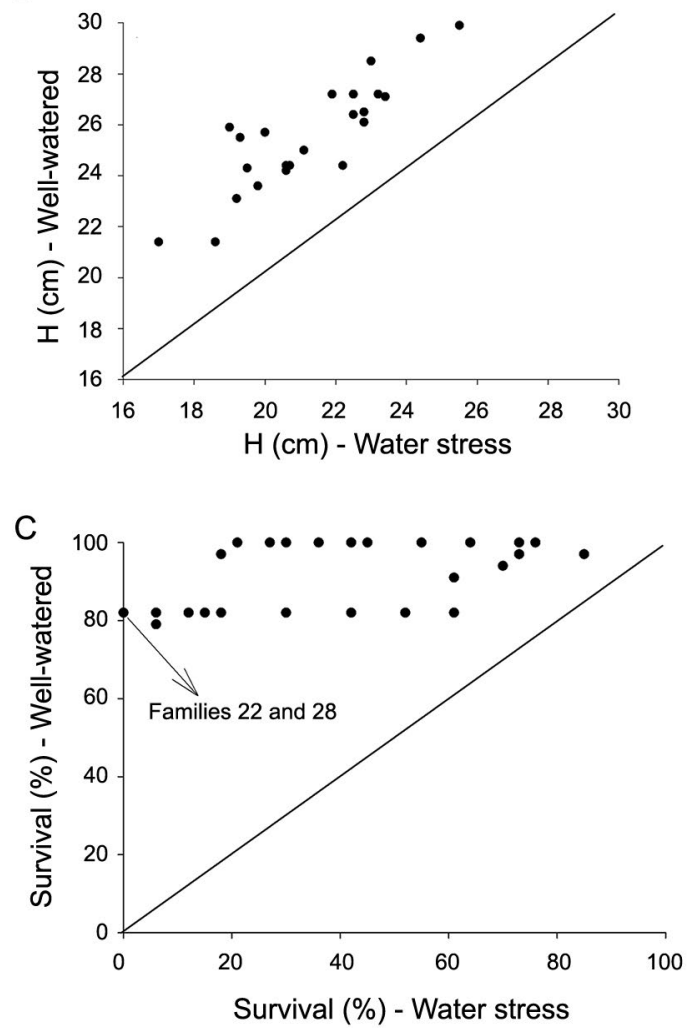

Figure 1 - Phenotypic plasticity analysis based on family means for growth and survival. $A=$ Root collar diameter; $B=$ height; $C=$ survival. Black dots represent average family APCI values.

(Table 1). In the case of Pearson correlations $\left(\mathrm{r}_{\mathrm{xy}}\right)$, a similar tendency in the nursery environments was observed for these three traits under study (i.e., a positive correlation), but a negative $(\mathrm{H})$ and non-significant (D and SUR) correlations between nursery and field were observed (Figure 2).

\section{Discussion}

There is controversy in studies estimating correlations between nursery and field trials. Some studies on coniferous species have reported positive correlations 
(Cannell et al., 1978; Tan et al., 1995); while, others have reported weak and negative correlations between family means for seedling and field traits (e.g., Carter et al., 1990; Jansson et al., 1998, 2005; Harfouche, 2003). In our study, except for survival, nursery-field correlations $\left(r_{g}\right.$ and $\left.r_{x y}\right)$ for growth traits were mostly negative and non- significant, due to:

1) We found that families in the nursery experiment exhibited a marked phenotypic plasticity, especially in

Table 1 - Estimated genetic correlations (environment-environment) \pm standard error or growth traits and survival in the 30 openpollinated $P$. radiata families under study.

\begin{tabular}{lccc}
\hline \multirow{2}{*}{ Trait } & \multicolumn{3}{c}{ Environment } \\
\cline { 2 - 4 } & WS-WW & WW-FT & WS-FT \\
\hline D & $0.71 \pm 0.07$ & $-0.70 \pm 0.45$ & $-0.65 \pm 0.45$ \\
H & $0.90 \pm 0.01$ & $-0.99 \pm 0.20$ & $-0.99 \pm 0.13$ \\
SUR & N.A & N.A & $0.93 \pm 0.40$ \\
\hline
\end{tabular}

WS $=$ water-stress nursery, $\mathrm{WW}=$ well-watered nursery, $\mathrm{FT}=$ field trial. $\mathrm{D}=$ root collar diameter, $\mathrm{H}=$ Tree height, SUR = survival, N.A = Not applicable because most seedlings in the well-watered treatment were alive and only $1 \mathrm{~s}$ were assigned (no variation). the survival. Eight of 30 families exhibited over $80 \%$ survival in the well-watered treatment, but less than $20 \%$ survival in the water-stress treatment. Moreover, two of these eight families exhibited no survival in the water-stress treatment thus greatly contributing to the observed plasticity. Matheson et al. (1995) conducted an experiment with ten $P$. radiata families (five "interactive" families cf. five "stable" ones) grown in the greenhouse and then planted in the field and found that interactive families in the field were also interactive in the greenhouse environments, and suggested that negative correlations are abundant for interactive families. A possible interpretation of the results of Matheson et al. (1995) is that plasticity at nursery stage (i.e., the presence of eight highly plastic families) contributed to the inconsistent correlations between nursery environments and experimental field site.

2) Ontogeny for seedlings in the nursery environments should be taken into account. Seedlings in our nursery experiments were in the primary needles stage (Williams, 1987), that is, before the formation of dwarf shoots, reflecting a less developed ontogenetic stage.


Figure 2 - Pearson coefficient of correlation between family means for growth traits and survival in the three environments analyzed. Root collar diameter (left panels A, B, C), height (center panels D, E, F), survival (right panels $G, H, I$ ). WW = well-watered; WS $=$ water-stress. 
Lascoux et al. (1993) suggested that seedlings must attain a minimum development stage (i.e. the threshold hypothesis) before juvenile traits become a reliable selection criteria. This may be explained by the different set of genes expressed at young and mature ages (Jansson et al., 1998, 2005) that obscure genetic relations between early and later-age growth. Williams (1987) defined this "threshold" stage for Pinus taeda L. seedlings when secondary needles emerge and budset begins. In this sense, we believe that negative nurseryfield correlations found by Harfouche (2003) with $P$. pinaster could be explained by early shoot ontogeny of one-month old seedlings. Thus, this critical point of morphogenetic change may have had a major influence on our incongruent results, suggesting that seedlings in more advanced shoot development stages should be used in early selection tests.

3) Lack of resemblance between conditions at nursery and field may have also accounted for our inconsistent results. It is known that extreme and highly limiting early growing conditions generally result in higher $\mathrm{G}$ $\times \mathrm{E}$ interaction effects, reducing nursery-field correlations (Eriksson et al., 1993; Li et al., 1991). In our nursery experiment, only the well-watered condition approximately resembled the plant water status in the field. However, seedlings in the water-stress treatment experienced an average $\Psi_{\mathrm{pd}}$ of $-1.5 \mathrm{MPa}$ and were severely stressed (survival was $44 \%$ on average), in a stark contrast with trees in the experimental field site, which experienced an average water potential of -0.6 MPa and were not severely damaged (survival reached $74 \%)$. This supports the contention by Harfouche (2003) and Jansson et al. (1998) that designing early tests that strictly simulates the limiting factor occurring later in a rotation improves the genetic correlations between early and late measurements.

We conclude that the growth and survival response of the 30 families studied here were not consistent between nursery and field conditions. Neither well-watered nor water-stress nursery treatments predicted the growth performance in field conditions. The family plasticity at nursery stage had a strong effect on our results. Thus, it should be carefully considered in future research to obtain reliable nursery-field correlations in $P$. radiata.

\section{Acknowledgements}

We are indebted to Dr. Verónica Emhart, Mr. Alex Medina and Mr. Lionel Rivera from Forestal Mininco S.A. for producing the seedlings to carry out this experiment and for financially supporting the field trial establishment and measurement. First author was supported by CONICYT grant $\mathrm{N}^{\circ}$ 79150013. This research was funded by FONDECYT (Initiation into Research Project $\mathrm{N}^{\circ} 11121484$ "Identification of Pinus radiata D. Don families suitable to be established in dryland areas").

\section{Authors' Contributions}

Conceptualization: Espinoza, S.E.; Ivković, M.; Magni, C.R. Data acquisition and analysis: Espinoza, S.E.; Ivković, M. Editing and critical review: Ivković, M.; Magni, C.R.; Yañez, M.; Santelices, R.; Cabrera, A.

\section{References}

Burdon, R.D. 1977. Genetic correlation as a concept for studying genotype-environment interaction in forest breeding. Silvae Genetica 26: 168-175.

Cannell, M.G.R.; Bridgwater, F.E.; Greenwood, M.S. 1978. Seedling growth rates, water stress responses and shoot-root relationships related to eight-year volumes among families of Pinus taeda L. Silvae Genetica 27: 237-248.

Carter, K.K.; Adams, G.W.; Greenwood, M.S.; Nitschke, P. 1990. Early family selection in jack pine. Canadian Journal of Forest Research 20: 285-291.

Chambel, M.R.; Climent, J.; Alía, R. 2007. Divergence among species and populations of Mediterranean pines in biomass allocation of seedlings grown under two watering regimes. Annals of Forest Science 64: 87-97.

Eriksson, G.; Jonsson, A.; Dormling, I.; Norell, L.; Stener, L.G. 1993. Retrospective early tests of Pinus sylvestris L. grown under five nutrient regimes. Forest Science 39: 95-117.

Espinoza, S.E.; Magni, C.R.; Martínez, V.A.; Ivković, M. 2013. The effect of water availability on plastic responses and biomass allocation in early growth traits of Pinus radiata D. Don. Forest Systems 22: 3-14

Espinoza, S.; Martínez, V.; Magni, C.; Ivković, M.; Santelices, R.; Cabrera, A. 2014. Genetic control of growth, biomass allocation and survival under drought stress in Pinus radiata D. Don seedlings. Tree Genetics and Genomes 10: 1045-1054.

Espinoza, S.; Magni, C.; Rubilar, R.; Yañez, M.; Santelices, R.; Cabrera, A.; Ivković, M. 2017. Field performance of various Pinus radiata breeding families established on a drought-prone site in central Chile. New Zealand Journal of Forest Science 47: 12.

Harfouche, A. 2003. Retrospective early test for adult vigor of Pinus pinaster families grown under two water regimes. Implications for early selection. Annals of Forest Science 60: 539-547.

Hodge, G.R.; White, T.L. 1992. Genetic parameter estimates for growth traits at different ages in slash pine and some implications for breeding. Silvae Genetica 41: 252-262.

Huber, A.; Trecaman, R. 2004. Water-use efficiency for Pinus radiata stands in Chile = Eficiencia del uso del agua en plantaciones de Pinus radiata en Chile. Bosque 25: 33-43 (in Spanish, with abstract in English).

Instituto Forestal [INFOR]. 2018. Chilean Forestry Sector 2017 = El Sector Forestal Chileno 2017. INFOR, Santiago, Chile. Available at: http://wef.infor.cl/sector_forestal/sectorforestal. php\#/10 [Accessed May 15, 2018] (in Spanish and English).

Intergovernmental Panel on Climate Change [IPCC]. 2013. Summary for policymakers. p. 1-27. In: Stocker, T.F.; Qin, D.; Plattner, G-K.; Tignor, M.; Allen, S.K.; Boschung, J.; Nauels, A.; Xia, Y.; Bex, V.; Midgley, P.M., eds. Climate change 2013: the physical science basis. Cambridge University Press, Cambridge, UK. 
Jansson, G.; Jonsson, A.; Eriksson, G.W. 1998. Efficiency of early testing in Pinus sylvestris L. grown under two different spacings in growth chamber. Silvae Genetica 47: 298-306.

Jansson, G.; Jonsson, A; Eriksson, G. 2005. Use of trait combinations for evaluating juvenile-mature relationships in Picea abies (L.). Tree Genetics and Genomes 1: 21-29.

Lascoux, D.M.; Paino, E.N.; Sierra-de-Grado, R.; Kremer, A.; Dormling, I. 1993. Maturation of maritime pine (Pinus pinaster Ait.) seedlings after exposure to a period of continuous light. Tree Physiology 12: 363-378.

Li, B.; McKeand, S.E.; Allen, H.L. 1991. Seedling shoot growth of loblolly pine families under two nitrogen levels as related to 12-year height. Canadian Journal of Forest Research 21: 842-847.

Matheson, A.C.; Spencer, D.J.; Kriedemann, P.E. 1995. Ageage correlation and early selection in radiata pine. I. Family $\mathrm{x}$ environment interactions in plantation and greenhouse. Australian Forestry 58: 35-43.
Mead, D.J. 2013. Sustainable Management of Pinus radiata Plantations. FAO, Rome, Italy.

Pigliucci, M.; Schlichting, C.D. 1996. Reaction norms of Arabidopsis. IV. Relationships between plasticity and fitness. Heredity 76: 427-436.

Tan, W.; Blake, T.J.; Boyle, T.J.B. 1995. Early selection for drought tolerance and relationship to dry weight partitioning in black spruce families. Forest Science 41: 168-180.

Williams, C.G. 1987. The influence of shoot ontogeny on juvenile-mature correlations in loblolly pine. Forest Science 33: 411-422. 